\title{
Correction to: Constituent of information governance framework for a successful implementation in Nigerian Universities
}

\section{Jika Saidu Muhammad ${ }^{1}$ - Azman Mat Isa ${ }^{1}$ - Ahmad Zam Hariro Samsudin ${ }^{1}$. Shah Jahan Miah²}

Published online: 1 October 2021

(c) Springer Science+Business Media, LLC, part of Springer Nature 2021

\section{Correction to: Educ Inf Technol (2021) 26(5):6447-6460 https://doi.org/10.1007/s10639-021-10528-w}

In the original version of this article, the name of the 3rd author was incorrectly spelled. The correct name of the 3rd author is "Ahmad Zam Hariro Samsudin," which is now correct in this article.

The authors apologize for the oversight and for any confusion it may have caused.

Publisher's note Springer Nature remains neutral with regard to jurisdictional claims in published maps and institutional affiliations.

The original article can be found online at https://doi.org/10.1007/s10639-021-10528-w.

Shah Jahan Miah

shah.miah@newcastle.edu.au

Jika Saidu Muhammad

msaidujika@gmail.com

Azman Mat Isa

azmanmi@uitm.edu.my

Ahmad Zam Hariro Samsudin ahmadzam@uitm.edu.my

1 Faculty of Information Management, Universiti Teknologi MARA Selangor Branch, Puncak Perdana Campus, 40150 Shah Alam, Selangor, Malaysia

2 Newcastle Business School, Newcastle, NSW, Australia 